\title{
Use of paracetamol for suicide and non-fatal poisoning in the UK and France: are restrictions on availability justified?
}

\author{
David Gunnell, Keith Hawton, Virginia Murray, Robert Garnier, Chantal Bismuth, \\ Joan Fagg, Sue Simkin
}

\begin{abstract}
Objective - To investigate the relationship between the availability of paracetamol and its use for overdose and suicide.

Design - Analysis of routinely collected information on time trends for paracetamol suicides, non-fatal overdoses, and sales.
\end{abstract}

Setting - England and Wales and France. Results - There were strong correlations between trends in paracetamol sales in the UK and trends in non-fatal paracetamol overdose in Oxford between 1976 and 1993 (Spearman's $r=0.86 ; 95 \%$ confidence interval (CI) 0.54, 0.96) and between paracetamol sales and non-fatal overdoses in France between 1974 and $1990(r=0.99$; 95\% CI 0.97, 1.00). Sales figures were also correlated with paracetamol related suicides in both England and Wales, 1983-91 $(\mathbf{r}=0.72 ; 95 \%$ CI $0.11,0.94)$ and France, 1974-90 ( $r=0.79$; 95\% CI 0.50, 0.92). Similarly strong relationships were observed between trends in non-fatal overdoses and suicide by paracetamol poisoning in England and Wales $(r=0.85 ; 95 \%$ CI $0.61,0.95)$ and France $(r=0.79 ; 95 \%$ CI $0.50,0.92)$. It is estimated that approximately 32000 overdoses involving paracetamol occur annually in England and Wales. Fatality rates from paracetamol overdose were four times as high in England and Wales $(0.4 \%, 95 \%$ CI $0.38,0.46)$ as in France (0.1\%, 95\% CI 0.06, 0.17).

Conclusion - Trends towards greater availability of paracetamol are parallelled by increases in its use for both non-fatal overdose and suicide. Paracetamol related morbidity and mortality seem to be less frequent in France where the quantity of paracetamol in a single purchase is limited. Although not conclusive, these data add to a body of evidence which suggests that restrictions in the quantity of paracetamol available as a single purchase in the UK may reduce suicide and liver failure related to paracetamol.

(f Epidemiol Community Health 1997;51:175-179)

Department of Acute Toxicology, Hopital Fernand Widal,

Paris, France

C Bismuth

Correspondence to: Dr D Gunnell.

Accepted for publication November 1996
Paracetamol is safely used by millions of people worldwide and is generally recognised to be an effective and safe analgesic. In England and Wales, however, at least $100-150$ people a year die as a result of paracetamol poisoning and over the last 20 years the number of deaths attributable to this has increased. ${ }^{1}$ Data from the Oxford monitoring system for attempted suicide indicate that the proportion of overdoses associated with paracetamol has increased threefold since $1976 .{ }^{23}$ Paracetamol overdose is also the most common cause of fulminant liver failure in the UK. The Birmingham Liver Unit admits about 60 patients per year with serious paracetamol toxicity and 66 of these patients were seen by the Kings College Hospital Liver Unit in an 18 month period in 1988-90. ${ }^{45}$ About $15-20$ patients a year undergo liver transplantation after paracetamol overdose in the UK. ${ }^{46}$ (Personal communication: Roger Williams.) The problems associated with paracetamol arise only when taken in overdose and recent evidence shows that most of those in the UK who take the drug in overdose realise its potential to cause serious harm.

It has been suggested that making the means of suicide less accessible to patients may result in reductions in method specific suicide rates and in overall suicides. ${ }^{89}$ In this paper we examine trends in paracetamol poisoning in countries where the availability of paracetamol differs - England and Wales and in France. In England and Wales paracetamol is freely available in unlimited quantities from chemists and up to $12 \mathrm{~g}$ may be purchased from supermarkets. In France paracetamol may only be purchased from pharmacies and the contents of each pack of paracetamol is legally limited to $8 \mathrm{~g}$. Our aims were to investigate whether trends in the availability of paracetamol affect the frequency of both non-fatal overdoses and suicides in which paracetamol is used, and to determine if differences in the availability of paracetamol in England and Wales and France affect morbidity and mortality from paracetamol overdose.

\section{Methods}

UK DATA ON PARACETAMOL POISONING

Several sources of information were used. Annual paracetamol mortality statistics for England and Wales 1975-91, which record only definite paracetamol related deaths, have been published and these were used in our analyses. ${ }^{1}$ No national data on the incidence of paracetamol overdose exist. We therefore used information from the Oxford monitoring system for attempted suicide. This records details of all patients attending the general hospital in 


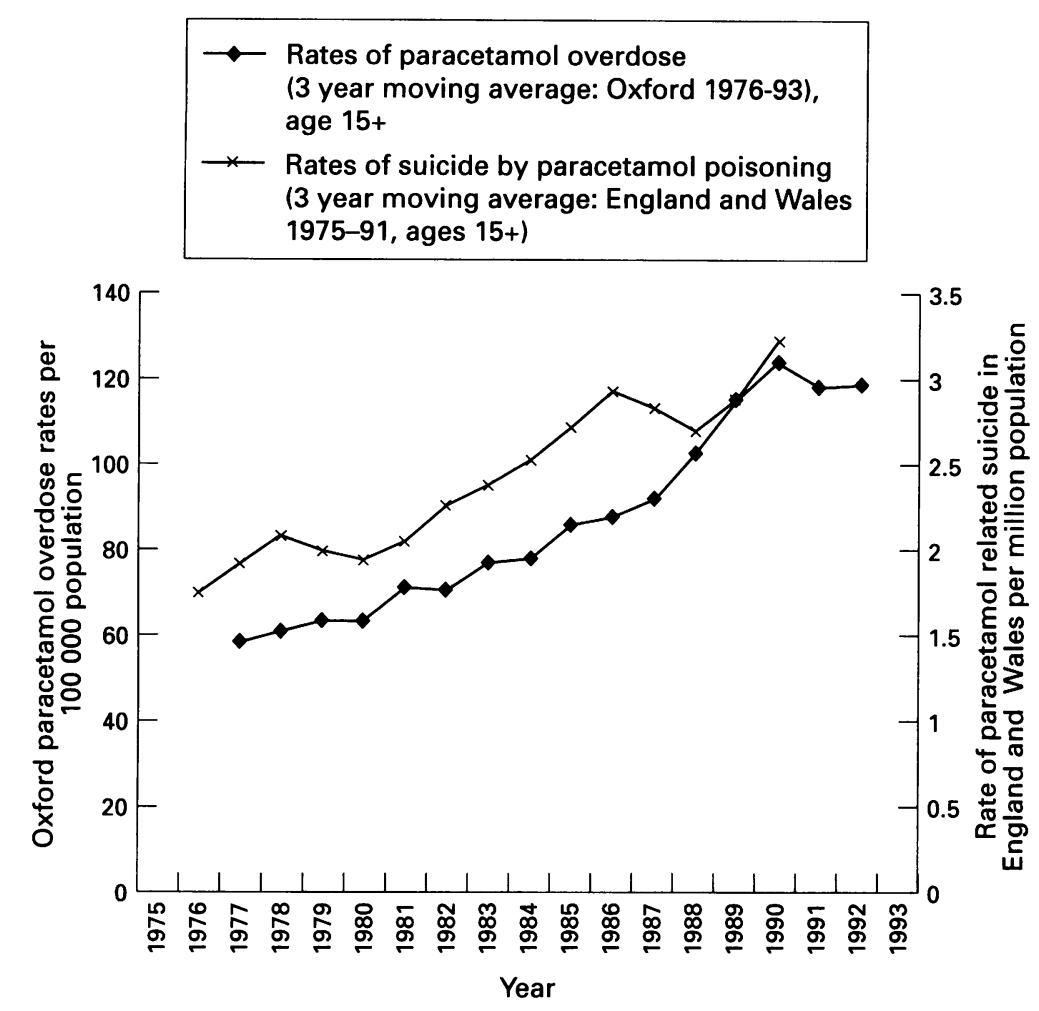

Figure 1 Rates of paracetamol related overdose in the city of Oxford (1976-93) and paracetamol suicide in England and Wales (1975-91).

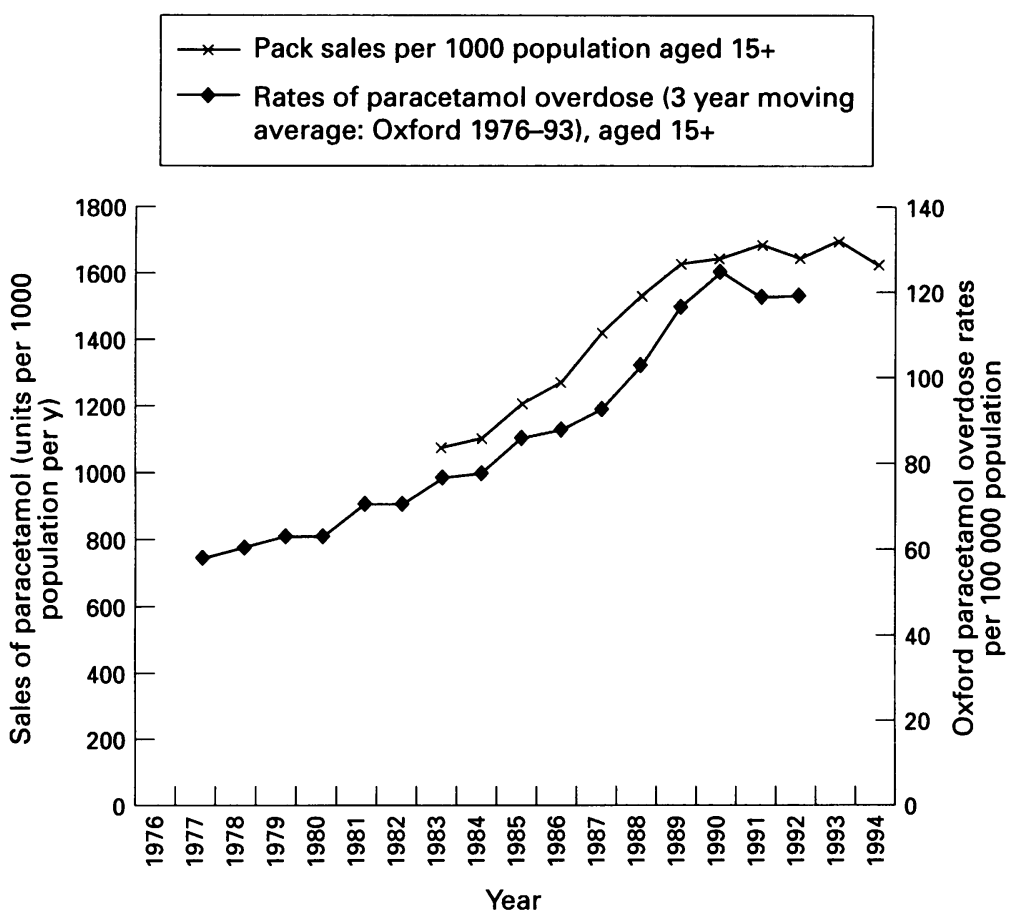

Figure 2 Relationship between sales of paracetamol in the United Kingdom (1983-94) and rates of paracetamol overdose in the city of Oxford (1976-93).

Oxford following an episode of self harm. ${ }^{23}$ Similar patterns of self harm having been found in other centres in the UK. ${ }^{101314}$ Person-based paracetamol overdose rates were calculated for the city of Oxford for 1976-93. These were used as indicators for national trends. The Oxford monitoring system does not differentiate overdoses of pure paracetamol from those of paracetamol containing products (eg co-proxamol), but, on the basis of examination of original data collection forms for sample periods, it was found that over the years of the study there was no significant change in the proportion of paracetamol overdoses involving pure paracetamol $(76.7 \%$ of all paracetamol overdoses, 92/120).

Information on sales of units of paracetamol (including paracetamol compounds) within the UK for 1983-94 was obtained from Intercontinental Medical Statistics Ltd, Middlesex. The figures used here are the total number of units (packets or bottles of paracetamol tablets of varying size) sold over the counter in chemists, supermarkets, or groceries in the UK in these years.

Spearman's correlation coefficients were calculated to examine associations between trends in annual figures for suicide involving paracetamol, overdoses with paracetamol, and sales of paracetamol. Three year moving average rates of paracetamol overdose and suicide were also calculated and these are shown in the figures to demonstrate trends over time. The population of the city of Oxford aged 15 and over and the total population of England and Wales aged 15 and over for the relevant years were used as denominators to calculate rates.

DATA ON PARACETAMOL POISONING IN FRANCE No comprehensive national recording of paracetamol related mortality and morbidity exists in France. Data on mortality and morbidity from paracetamol poisoning in France were obtained from data routinely collected by French poisons centres for 1974-90. The data collected were on paracetamol overdoses and paracetamol related deaths reported to these centres between 1974 and 1990. These data were obtained from Centres Anti-Poisons in: Angers, Bordeaux, Clermont-Ferrand, Grenoble, Lille, Lyon, Marseille, Montpellier, Nancy, Paris, Reims, Rennes, Rouen, Strasbourg, and Toulouse. The extent of underreporting of paracetamol poisoning to French poisons centres is not known, but it is estimated that the actual number of episodes may be 2-10 times higher than reported cases. Underreporting of severe cases of poisoning is likely to be less frequent than for more trivial cases.

As the populations served by the French poison's centres are not clearly defined, the results are reported as numbers of episodes rather than rates. Spearman's correlation coefficients were calculated based on the number of episodes in each year. Three year moving average numbers of paracetamol overdoses and suicides were calculated and these are used in the figures. As for the British data, paracetamol sales in France were obtained from Intercontinental Medical Statistics Ltd.

\section{Results}

PARACETAMOL POISONING IN ENGLAND AND WALES

Figure 1 shows the relation between paracetamol suicide rates (1975-91) for England 


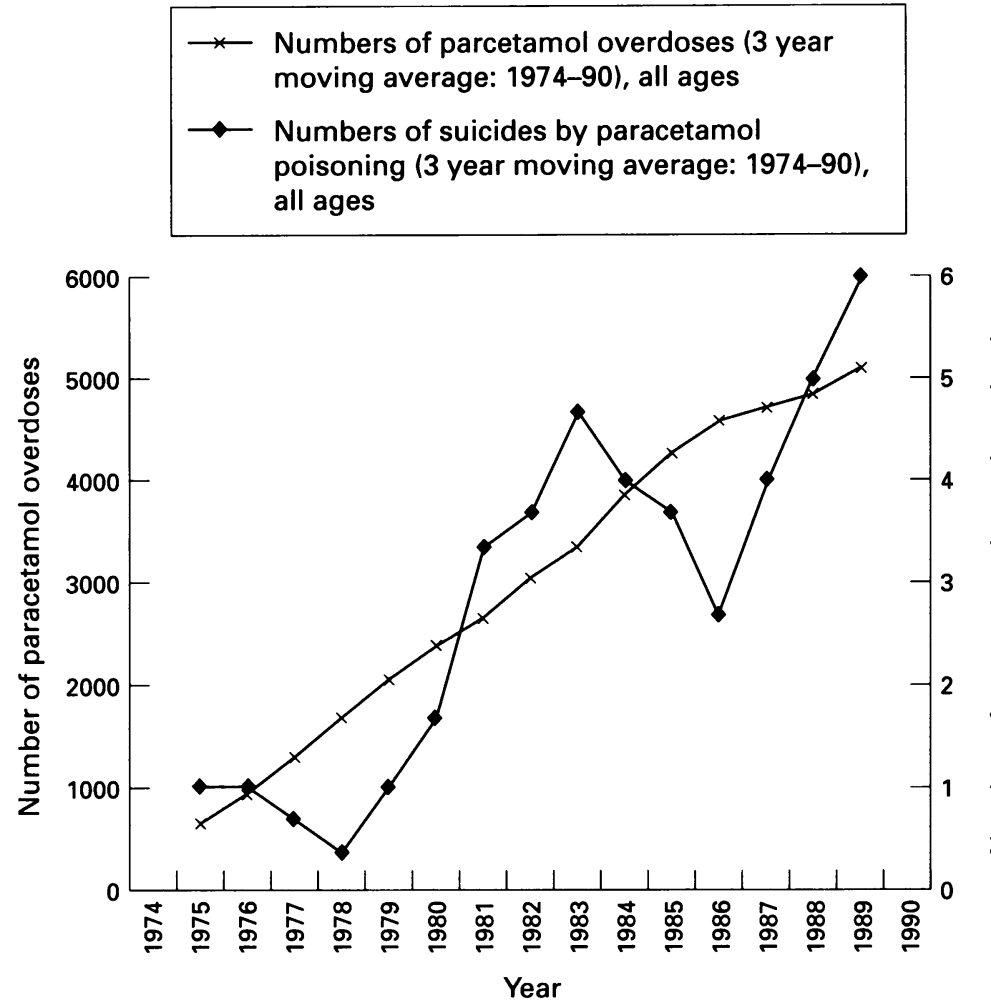

Figure 3 Paracetamol related overdose and suicide in France (1974-90).

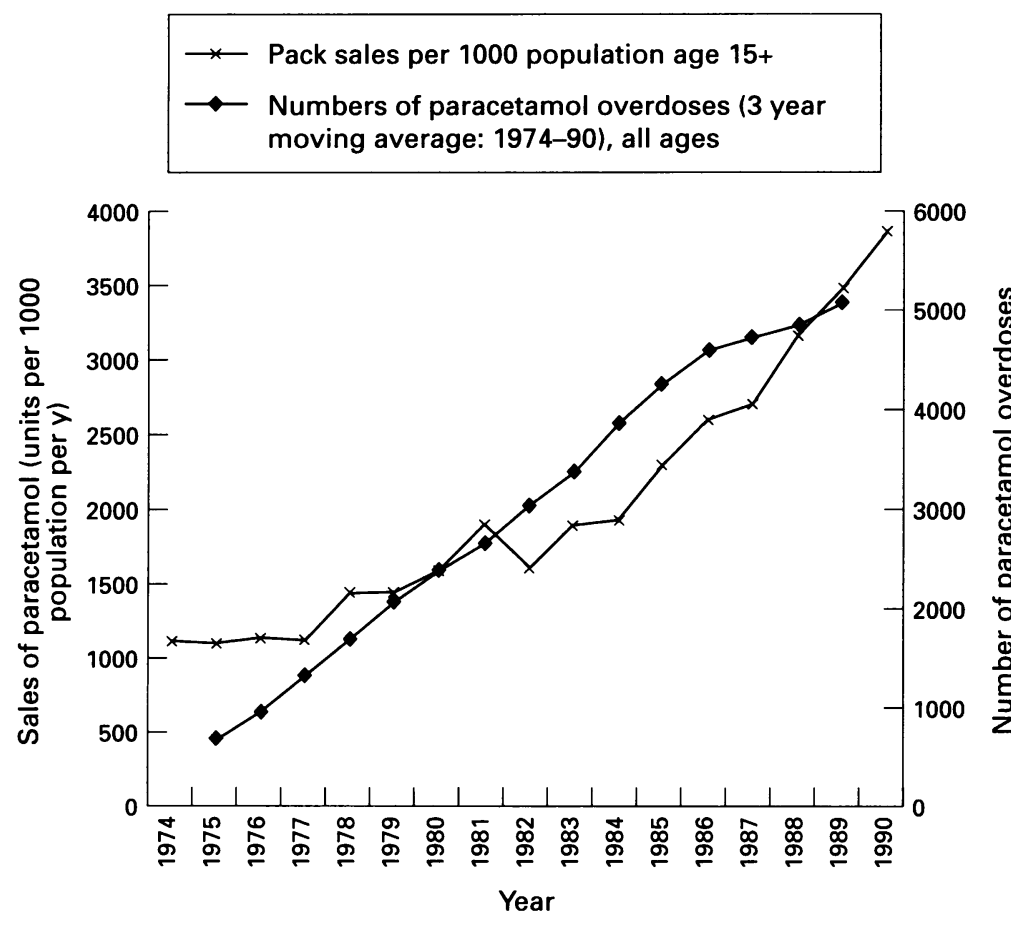

Figure 4 Relationship between paracetamol sales and paracetamol overdose in France (1974-90). per 1000 population (1983-94) and paracetamol overdose rates in Oxford between 1976-93 (Spearman's rank correlation coefficient for the annual rates between 1983 and $1993=0.86 ; 95 \%$ CI $0.54,0.96)$. The correlation between annual paracetamol related suicide rates and paracetamol sales per 1000 population between 1983 and 1991 was 0.72 (95\% CI $0.11,0.94)$.

A crude estimate of the total number of paracetamol overdoses in England and Wales can be made from the Oxford monitoring system. In 1989-91 there were 376 hospital referred paracetamol overdoses in Oxford. If the age specific rates of paracetamol overdose in Oxford are extrapolated to the population of England and Wales an estimated 41200 hospital referred cases of overdose of paracetamol containing products would have occurred annually. Of these, approximately 32000 overdoses were likely to have been of "pure" paracetamol (see methods). During 1989-91 there were 400 definite paracetamol overdose deaths in England and Wales. Thus, an estimated case fatality rate of $0.4 \%$ ( $95 \%$ CI $0.38,0.46$ ) following paracetamol overdose was seen over these years.

PARACETAMOL MORTALITY, MORBIDITY, AND SALES IN FRANCE

Figure 3 shows the relationship between paracetamol overdoses and mortality from paracetamol overdoses in France between 1974 and 1990 (Spearman's $\mathrm{r}$ for annual figures: $0.79 ; 95 \%$ CI $0.501,0.92$ ). Figure 4 shows the relationship between paracetamol sales and overdose rates over this same time-span (Spearman's $\mathrm{r}$ for annual figures: $0.99 ; 95 \%$ CI 0.97 , 1.00). The correlation between yearly sales and suicides was $0.79(95 \%$ CI $0.50,0.92)$. Over the years 1988-90 there were 18 recorded fatalities and 15231 recorded overdoses, giving a case fatality rate of $0.1 \%(95 \%$ CI $0.06,0.17)$.

\section{Discussion}

We have found a clear relationship between trends in paracetamol sales and use of the drug for overdose. This is in keeping with evidence that trends in the rate at which a particular drug is used for suicide relate to the availability of that drug. In England and Wales reduction in suicides using sedatives, tranquillisers, and hypnotics has mirrored a reduction in the prescribing of these drugs. ${ }^{11}$ Similarly, in Australia restrictions placed on the quantities of barbiturate that could be dispensed at one time led to reductions in barbiturate suicides. ${ }^{12} \mathrm{We}$ also found that mortality following paracetamol overdose was higher in England and Wales than in France - perhaps because of differences in the quantity of drug available in a single purchase.

\section{LIMITATIONS OF DATA}

There are possible limitations to using data from several different sources, although we have no reason to suspect that these will have 
biased our results. Sales data for the two countries came from the same source and should therefore be comparable. Sales units rather than the exact quantity of paracetamol sold were used as these were considered the best measure of drug availability. Paracetamol overdose rates for England and Wales over the timespan of this analysis were not available. We therefore used data from the Oxford monitoring system for attempted suicide; similar patterns of self harm having been found in Edinburgh. ${ }^{10}$ We have no means of determining whether the trends observed in Oxford are representative of patterns elsewhere in England and Wales, although similar increases in paracetamol overdose have been reported in Northern Ireland ${ }^{13}$ and Scotland. ${ }^{14}$ In France detailed records of paracetamol overdose and suicide do not exist and therefore data routinely collected by French poison's centres were used. The representativeness of this information is unknown as the poison's centres have no clear catchment population and for this reason we were unable to calculate rates of paracetamol overdose or suicide. For comparison we also calculated the correlation coefficients for the British data in this way. If anything the correlation coefficients were greater when episodes rather than rates were used (suicide and parasuicide: $r=0.88$; sales and suicide: $r=0.72$ and sales and parasuicide: 0.94 ).

A more serious problem relates to our use of time trends to examine the correlation between two variables over time. Correlations found in such analyses do not necessarily imply that a causal relationship exists between the correlated variables. Indirect support for a causal link between the time trends we observed comes from data on aspirin sales, overdoses, and suicides. Reduction in sales of aspirin in the United Kingdom (personal communication, Intercontinental Medical Statistics) have been accompanied by reductions in aspirin overdose rates in Oxford and this decline is parallelled by a decline in suicide by aspirin. ${ }^{12}$ Thus increases in sales of paracetamol have been accompanied by increases in paracetamol overdose whereas decreases in aspirin sales have been accompanied by decreases in its use in overdose. These divergent trends add further support to the hypothesis that availability of drugs within the home (as measured by sales figures) is related to their use for self harm.

\section{PARACETAMOL RELATED MORBIDITY AND} MORTALITY IN RELATION TO AVAILABILITY In England and Wales there is evidence of both considerable morbidity (an estimated 32000 overdoses and 15-20 liver transplants per year) and sizeable mortality (up to 150 deaths per year) from paracetamol overdose. This morbidity is largely experienced by those in younger age groups, thereby making it all the more significant. Our data show that in Britain, as in France, there have been increases in the sales of paracetamol over the last 20 years. Increases in sales (ie availability) in England and France have been accompanied by increases in the use of paracetamol in fatal and non-fatal overdose. However, whereas the crudely estimated fatality rate in England and Wales is $0.4 \%$, the fatality rate in France is $0.1 \%$. Because French poisons centres are likely to be involved in more serious cases of paracetamol overdose, the French data may, if anything, overestimate paracetamol overdose mortality rates. A possible explanation for the difference in rates is that the quantity of drug available in a packet and at a single purchase is restricted to $8 \mathrm{~g}$ in France. Although, as already discussed, the accuracy of these fatality rates should be treated with some caution. The difference in fatality rates may arise because mortality was under-reported in the survey of French poisons centres, whereas rates in England and Wales were derived from drug-specific mortality data published by the Office of Populations Censuses and Surveys. ${ }^{1}$ Different patterns of morbidity in the two countries are, however, supported by data on enquiries to French and British poisons centres. Between 1974 and 1983, a poisons centre in Paris received 350000 calls, of which only 1600 $(0.46 \%)$ concerned paracetamol overdose. ${ }^{1516}$ In contrast, in 1994, some 15887 calls $(10.4 \%$ of all calls) to the National Poisons Information Service at Guys and St Thomas's Hospital concerned paracetamol overdose. (Personal communication, National Poisons Information Service, at Guys and St Thomas's Hospital).

Few published studies report data on fatality rates for paracetamol overdose. In the USA, where paracetamol is freely available, data from two studies suggest fatality rates of $0.2 \%{ }^{17}$ and $0.4 \% .{ }^{18}$ In Denmark paracetamol became available for over the counter sales in pharmacies in 1984. Sales there increased 47 fold in 1978 86 , the number of admissions for overdose increased eightfold, and suicides increased from 1 to $3-4$ per year. The Danish fatality rate was $1.5-2 \%$ among patients admitted to hospital with paracetamol overdoses. ${ }^{19}$

It might be argued that persons intent on suicide are able to make several independent purchases of small quantities of the drug to obtain a lethal dose. Recent research has shown, however, that around half of those who take paracetamol overdoses do not obtain the drug specifically for the overdose but use medicine available in the house at the time of distress. ${ }^{7}$ If purchase sizes were limited it is less likely that people would keep potentially lethal quantities of the drug around the house.

It is recognised that the short term lowering of suicide rates that results from reduced accessibility of particular methods may be lost with time. ${ }^{20}$ This does not mean that attempts to reduce the accessibility of particular suicide methods are not worthwhile. Indeed it is estimated that changes in the toxicity of the domestic gas supply in England and Wales resulted in the prevention of 6000 suicides. $^{21}$ It must be recognised, however, that some methods of suicide are likely to gain in popularity as restrictions are placed on others. One potential risk of making such changes is that the popularity of paracetamol may be reduced in favour of drugs such as psychotropics or preparations such as paraquat and other pes- 
ticides which are likely to be far more lethal. ${ }^{22}$ Generally, when paracetamol is taken in overdose in the UK it is usually relatively harmless, as suggested by the estimated fatality rate of around $0.4 \%$. If mere limitation of the quantity of paracetamol taken in overdose were achieved, without an effect on the overall number of paracetamol overdoses, the substitution of method effect would be unlikely to occur. Thus, there should be a significant reduction in the number of paracetamol suicides.

\section{Conclusions}

The data presented in this paper support the view that trends in the wider availability of paracetamol result in greater paracetamol related morbidity and mortality, although limitations of the data mean that these links are not conclusive. A number of approaches to limit the morbidity and mortality caused by paracetamol overdose are possible. Firstly, the quantity of paracetamol available for purchase and the ease of its availability could be limited. Currently up to $12 \mathrm{~g}$ of paracetamol may be purchased from supermarkets and other general stores, and there is no limit to the quantity of paracetamol which may be purchased from pharmacies. Secondly, adding methionine (an amino acid which protects against paracetamol's hepatotoxicity) to all paracetamol preparations may reduce the mortality and morbidity from overdose. ${ }^{23}$ Thirdly, the packaging of paracetamol within blister packs may make the swallowing of large numbers of tablets less easy and thus make fatal overdoses less common. Attention should also be paid to making the wording of warning labels on these packages more effective. Finally, publicity campaigns to warn of the dangers of paracetamol have been discussed, although these may have the paradoxical effect of increasing its use in overdose. ${ }^{24}$

It is recommended that the best course of action in the UK would be to limit the total quantity of paracetamol that may be purchased as a single item to less than $12 \mathrm{~g}$. In addition to this, restrictions on the sale of paracetamol to pharmacies should also be considered. Because of the risk of substitution of drugs, similar changes should also apply to over the counter sales of aspirin and other non-opiate analgesics. The rationale for such a policy is supported by recent evidence that those taking paracetamol overdoses from a loose container (ie a bottle) consume more tablets than those overdosing with paracetamol from a blister pack - the number of tablets per preparation being far fewer in blister pack preparations. ${ }^{25}$ Such a policy would not prevent all paracetamol related suicides but may result in a decrease in their incidence and a reduction in the need for subsequent liver transplantation.

The authors thank Dr D Vesque, Laboratoire UPSA, France. French Centres Anti-Poisons in: Angers, Bordeaux, ClermontFerrand, Grenoble, Lille, Lyon, Marseille, Montpellier, Nancy, Paris, Reims, Rennes, Rouen, Strasbourg and Toulouse; Intercontinental Medical Statistics Ltd, Middlesex, for provision of information on paracetamol sales. The Oxford Monitoring System for Attempted Suicide is funded by the Department of Health.

1 Spooner JB, Harvey JG. Paracetamol overdosage - facts not misconceptions. Pharm f 1993; 250:706-7.

2 Hawton K, Fagg J, Simkin S, Mills J, Bale E. Attempted suicide in Oxford 1993. Oxford: Oxford University Department of Psychiatry, 1994

3 Hawton K, Fagg J. Trends in deliberate self poisoning and self injury in Oxford, 1976-90. BMF 1992;304:1409-11.

4 O'Grady JG, Wendon J, Tan KC, Potter D, Cottam S, Cohen AT, Gimson AES, Williams R. Liver transplantation Cohen AT, Gimson AES, Williams R. Liver transplanta

5 Mutimer D, Ayres RCS, Neuberger JM et al. Serious paracetamol poisoning and the results of liver transplantation. Gut 1994;35:809-14.

6 Mutimer D. Paracetamol overdose - is there a role for liver transplantation? F Clin Pharm Therapeutics 1993; 18: 303-7.

7 Hawton K, Ware C, Mistry H, Hewitt J, Kingsbury S Roberts $\mathrm{D}$, Weitzel $\mathrm{H}$. Why patients choose paracetamol for self-poisoning and their knowledge of its dangers. $B M \mathcal{F}$ 1995;310: 164

8 Kreitman N. The coal gas story. Br $\mathcal{f}$ Prev Soc Med 1976; 30:86-93.

9 Gunnell D, Frankel S. Prevention of suicide: aspirations and evidence. $B M \mathcal{F}$ 1994;308:1227-33.

10 Platt S, Hawton K, Kreitman N, Fagg J, Foster J. Recent clinical and epidemiological trends in parasuicide in Edinburgh and Oxford: a tale of two cities. Psychol Med 1988; inburgh and

11 Charlton J, Kelly S, Dunnell K, Evans B, Jenkins R. Suicide deaths in England and Wales: trends in factors associated with suicide deaths. Popul Trends 1993;71:34-42.

2 Oliver RG, Hetzel BS. An analysis of recent trends in suicide rates in Australia. Int $\mathcal{F}$ Epidemiol 1973;2:91-101.

13 Quigley N, Galloway R, Kelly C. Changes in the pattern of deliberate self-poisoning presenting at Craigavon Area Hospital: 1976, 1986 and 1991. Ulster Med F 1994;63: 155-61.

14 McCloone P, Crombie IK. Hospitalisation for deliberate self-poisoning in Scotland from 1981 to 1993: Trends in rates and types of drug used. $B r f$ Psychiatry 1996:169. 81-85.

15 Bismuth C, Garnier R, Fournier PE, Baud F. Securité des conditionnements nationaux de paracetamol. Pas de mortalité française par intoxication aigue. La Presse Medicale 1983;12:1632-4.

16 Garnier R, Bismuth C. Liver failure induced by paracetamol. Letter. BMf 1993;306:718.

17 Litovitz TL, Bailey KM, Schmitz BF, Holm KC, KleinSchwartz W. 1990 Annual report of the American Association of Poison Control Centers national data collection system. Am f Emerg Med 1991;9:461-509.

18 Smilkstein MJ, Knapp GL, Kulig KW, Rumack BH. Efficacy of oral $\mathrm{n}$-acetylcysteine in the treatment of acetominophen overdose. Analysis of the national multicenter study (19761985). N Engl F Med 1988; 319: 1557-62.

19 Ott P, Dalhoff K, Hansen P, Loft S, Poulsen H. Consumption, overdose and death from analgesics during a period of over the counter availability of paracetaming a Denmark. F Intern Med 1990; 227: 423-8.

20 Ohberg A, Lonnqvist J, Sarna S, Vuori E, Penttila A. Trends and availability of suicide methods in Finland. $\mathrm{Br}$ T Psychiatry 1995; 166: 35-43.

21 Ofice of Health Econ: 35 . 3 . London: Office of Health Economics, 1981.

22 Berger LR. Suicides and pesticides in Sri Lanka. Am f Public Health. 1988;78:826-28.

23 Neuvonen PJ, Tokola O, Toivonen M, Simell O. Methionine in paracetamol tablets, a tool to reduce paracetamol toxicity. Int $\mathcal{f}$ Clin Pharmacol Ther Toxicol 1985;23: 497-500.

24 Bray G. Liver failure induced by paracetamol. BMF 1993; 306: $157-58$.

25 Hawton K, Ware C, Mistry H, Hewitt J, Kingsbury S, Roberts D, Weitzel H. Paracetamol self-poisoning: characteristics, prevention and harm reduction. $B r f$ Psychiatry 1996;165:43-48. 